\title{
Study of the phenotypic relationship in the IMR-32 human neuroblastoma cell line by Sedimentation Field Flow Fractionation
}

\author{
G. BÉGAUD-GRIMAUD ${ }^{1}$, S. BATTU ${ }^{1}$, P. LAZCOZ ${ }^{3}$, J.S. CASTRESANA ${ }^{3}$, \\ M.O. JAUBERTEAU ${ }^{2}$ and P.J.P. CARDOT ${ }^{1}$
}

\begin{abstract}
${ }^{1}$ Laboratoire de Chimie Analytique et Bromatologie, E.A. 3842, 'Homéostasie Cellulaire et Pathologies', Université de Limoges, Faculté de Pharmacie, ${ }^{2}$ Laboratoire d'Immmunologie, E.A. 3842, 'Homéostasie Cellulaire et Pathologies,' Faculté de Médecine, Université de Limoges, 2 rue du Docteur Marcland, 87025 Limoges Cedex, France; ${ }^{3}$ Molecular Neuro-Oncology Laboratory, Facultad de Medicina, University of Navarra, Pamplona, Spain
\end{abstract}

Received February 23, 2007; Accepted April 18, 2007

\begin{abstract}
Neuroblastoma (NB) is the most common childhood solid tumor. Although spontaneous regression can occur in patients $<1$-year old, $70 \%$ of patients over the age of 1 year have a high-risk and difficult-to-treat NB. Cell type heterogeneity is observed either in the morphological appearance of NB tumors or in cell lines isolated from tumor specimens. NB consists of two principal neoplastic cell types: i) neuroblastic or N-type (undifferentiated cells); and ii) stromal or S-type (differentiated cells). As NB cells seem to have the capacity to differentiate spontaneously in vivo and in vitro, their heterogeneity could affect treatment outcome, in particular the response to apoptosis induced by chemotherapy. Therefore, it is important to understand the underlying process governing changes in differentiation in order to improve treatment response and NB patient outcome and the neoplastic population in IMR-32 represented a good model for such a study. Results showed that this cell line was extremely heterogeneous and highly variable in its stage of differentiation and we demonstrated that sedimentation field flow fractionation (SdFFF) permitted the isolation of $2 \mathrm{~N}$-phenotypes and contributed to the understanding of the IMR-32 cell population dynamics. The first $\mathrm{N}$-phenotype forms a pool of quiescent undifferentiated cells while the second one was able to proliferate (incorporation of BrdU) and also give rise to adherent S-type cells (PSA$\mathrm{N}-C A M^{+}$and $\mathrm{N}-\mathrm{CAM}^{+}$). The results could also suggest a close interaction between these different cellular phenotypes to create the IMR-32 cell lineage.
\end{abstract}

Correspondence to: Dr S. Battu, Laboratoire de Chimie Analytique et Bromatologie, Faculté de Pharmacie, E.A. 3842, 'Homéostasie Cellulaire et Pathologies', Université de Limoges, 2 rue du Docteur Marcland, 87025 Limoges Cedex, France

E-mail: serge.battu@unilim.fr

Key words: neuroblastoma cell line, cellular phenotype, cell sorting, sedimentation field flow fractionation

\section{Introduction}

Neuroblastoma (NB) is the most common childhood solid tumor (1). This malignant tumor arises from abnormal arrest in differentiation of multipotent embryonal cells of the neural crest into normal adrenal medulla and postganglionic sympathic neurons (1). Although spontaneous regression can occur in patients $<1$-year old, $70 \%$ of patients over the age of 1 year have a high-risk and difficult-to-treat NB $(1,2)$. Diagnosis is characterized by amplification of the MYCN oncogene (MNA) on chromosome 2p24 (20-25\% of NB tumors) and the presence of metastases. However, despite the long-known prognostic impact of MNA in NB, the molecular mechanism by which MYCN is amplified still remains enigmatic $(3,4)$. Treatments used in NB include chemotherapy, surgery, radiotherapy and bone marrow transplantation (2). Compared to the early 1980s, the 5-year overall survival of children with stage $4 \mathrm{NB}$ has improved from about $10 \%$ to about $25 \%$ as a result of better treatment. However, long-term survival is still poor $(5,6)$. Thus, prognosis for children over 1 year of age remains unsatisfactory and finding new agents with therapeutic potential is of great clinical interest.

The neoplastic populations in NB are extremely heterogeneous and highly variable in their stage of differentiation (2). Cell type heterogeneity is observed either in the morphological appearance of NB tumors or in cell lines isolated from tumor specimens. NB consists of two principal neoplastic cells $(7,8)$ : i) neuroblastic or N-type: undifferentiated, round and small scant cytoplasm cells; and ii) stromal or S-type: large hyaline, flattened and adherent differentiated cells. As NB cells seem to have the capacity to differentiate spontaneously in vivo and in vitro (2), their heterogeneity could affect treatment outcome, in particular the response to apoptosis induced by chemotherapy. For this reason, it seemed important to understand the underlying process governing changes in differentiation in order to improve treatment response and NB patient outcome.

To answer this question, a first step would be to study the differentiation kinetics on separated and enriched subpopulations. The N-type sub-population could be of great interest in this goal. Secondly, these sub-populations could be 
used as a model in further investigations concerning apoptosis and differentiation induction as an anti-cancer treatment.

To achieve the first goal, we used a heterogeneous cell lineage: the human neuroblastoma IMR-32, which shows both $\mathrm{N}$ - and S-type cells in culture.

For cell sorting, we used sedimentation field flow fractionation (SdFFF). At present a wide array of techniques and methods are available for cell separation and characterization: centrifugation, elutriation, electrophoresis, fluorescence or magnetic-activated cell sorting (FACS and MACS), which take advantage of biophysical criteria (size, density, shape), electrical charge or specific antigen expression (9-14). SdFFF takes advantage of intrinsic biophysical properties of cells (size, density, shape or rigidity) (15-26) and combines possibilities of flow driven separation techniques (elutriation, chromatography) and of field induced and focusing techniques (electrophoresis, centrifugation) $(14,19,27,28)$. By using specific elution mode (Hyperlayer), SdFFF might be more useful than many other cell sorters to provide purified, viable and usable cell fractions because: i) no complex mobile phase and no long, expensive cell preparation or labeling are needed; ii) elution and sorting are very fast and gentle; and iii) because the device can be easily and rapidly optimized for each new separation procedure. As specific pre-labeling (fluorescent or magnetic) is not necessary (tagless method) (27), SdFFF is an interesting method for applications in which labels could interfere with further cell uses (culture, transplantation, immunoblotting), when labels do not exist or when labels could induce cell differentiation (14,27-29).

The fundamental principle of field flow fractionation is based on the differential elution of species submitted to the combined action of: i) a parabolic profile generated by flowing a mobile phase through a ribbon-like capillary channel; and ii) an external field perpendicularly applied to the flow direction $(18,19)$. In SdFFF, a multigravitational external field is generated by the rotation of the separation channel in a rotor basket, constituting one of the most complex devices used in FFF separation $(11,19,28)$.

Since the work of Caldwell et al (16) on mammalian cells, FFF and related technologies have been used in many biological fields such as hematology, microorganism analysis, biochemistry/biotechnology and molecular biology, or cancer research $(14,27,30-47)$. Recently, we have opened the field of neurosciences by the purification of neurons from embryonic cortical cell suspensions (48), immature neural cell fractions from cancer cell lines (49), or immature neural cell fractions which could behave similarly to stem cells from embryonic avian olfactory epithelium (29). For several years, we have investigated the implication of SdFFF in cancer research, in particular to study chemical apoptosis or differentiation induction in a cancer cell line (50). Different applications of this technique include: i) the monitoring of the biological event (detection and characterization) (51-54); ii) cell sorting of specific sub-populations such as pre-apoptotic (52), or differentiated cells (54) which could be used as a model; and iii) the kinetics of the biological event using both the monitoring and cell separation capacities of SdFFF.

These studies, in association with the previous results concerning the human SH-SY5Y clone of the SK-N-SH cell line (49), demonstrated the interest of SdFFF cell sorting to study the differentiation kinetics in the IMR-32 NB cell line.

We first characterized cells in the IMR-32 cell line based on specific antigen expression: i) expression of nestin and PSA-N-CAM (PolySialylated Acid-Neural Cell Adhesion Molecule) in immature neural cells; ii) expression of N-CAM (Neural Cell Adhesion Molecule) and NF (NeuroFilament) in differentiated specific cells i.e. neurons; and iii) expression of GFAP (Glial Fibrillary Acidic Protein) in astrocytes. The expression of the death receptor, Fas, was investigated in SdFFF cell fractions to determine the degree of cell maturation. Then, the capacity of SdFFF to sort N- and S-type cells was investigated. Cell culture, specific antigen expression and proliferation studies were conducted as a function of cellular fraction and culture time to establish the phenotypic relationship and to understand the kinetic processes implicated in differentiation.

For the first time, our results demonstrated the capability of SdFFF to sort two phenotypes of N-type cells. One contained quiescent undifferentiated cells expressing low levels of markers such as Fas or nestin. The second corresponded to proliferative undifferentiated cells $\left(\mathrm{Fas}^{+}\right.$, nestin $\left.{ }^{+}, \mathrm{N}-\mathrm{CAM}^{-}\right)$from which differentiation occurred. SdFFF cell sorting allowed, followed by marker expression and kinetic studies, the understanding of the differentiation process and the relationship which exists between S-type and N-type cells.

\section{Materials and methods}

Cell line, cell culture and light microscopy. The IMR-32 human neuroblastoma cell line employed in this study was kindly provided by Dr Javier S. Castresana (Molecular Neuro Oncology Laboratory, University of Navarra, Pamplona, Spain). Cells were cultured in D-minimum essential medium high glutamax (Invitrogen, Paisley, Scotland) supplemented with $10 \%$ heat inactivated foetal bovine serum (FBS, South American, invitrogen), $10 \%$ non-essential amino acids $100 \mathrm{X}$ (Invitrogen), 100 units/ml penicillin (Gibco-BRL/Life Technologies, Paisley, Scotland) and $100 \mu \mathrm{g} / \mathrm{ml}$ streptomycin (Gibco$\mathrm{BRL}$ ). Cultures were maintained in a humid atmosphere at $37^{\circ} \mathrm{C}$ with $5 \% \mathrm{CO}_{2}$. After removing medium, cells were washed in phosphate buffer saline (PBS, pH 7.4, Gibco-BRL). Freshly versenized, $10^{6}$ cells were seeded in $75 \mathrm{~cm}^{2}$ tissue culture flasks (Nunc, Fisher Bioblock Scientific, Illkrich, France) for 3 days before SdFFF analysis. Neuroblastoid and fibroblastoid cells were versenized, combined, counted and cell viability was determined by trypan blue exclusion: cell concentration was adjusted to $2.5 \times 10^{6}$ cells $/ \mathrm{ml}$ PBS (control) before SdFFF analysis. After SdFFF analysis, control and eluted cells were seeded $\left(5 \times 10^{5}\right.$ cells/well) in 8 -well Permanox Lab-Tek ${ }^{\circledR}$ Chamber Slides (Nunc, Fisher Bioblock Scientific). For light microscopy, cultured cells were examined under phase-contrast microscopy (magnification x200). Photographs were taken with a Nikon camera (Champigny-sur Marne, France).

SdFFF device and cell elution conditions. SdFFF separation device used in this study derived from those previously described and schematized $(28,52,54)$. The apparatus was composed of two $938 \times 40 \times 2 \mathrm{~mm}$ polystyrene plates, separated by a mylar ${ }^{\circledR}$ spacer in which the channel was curved. Channel 


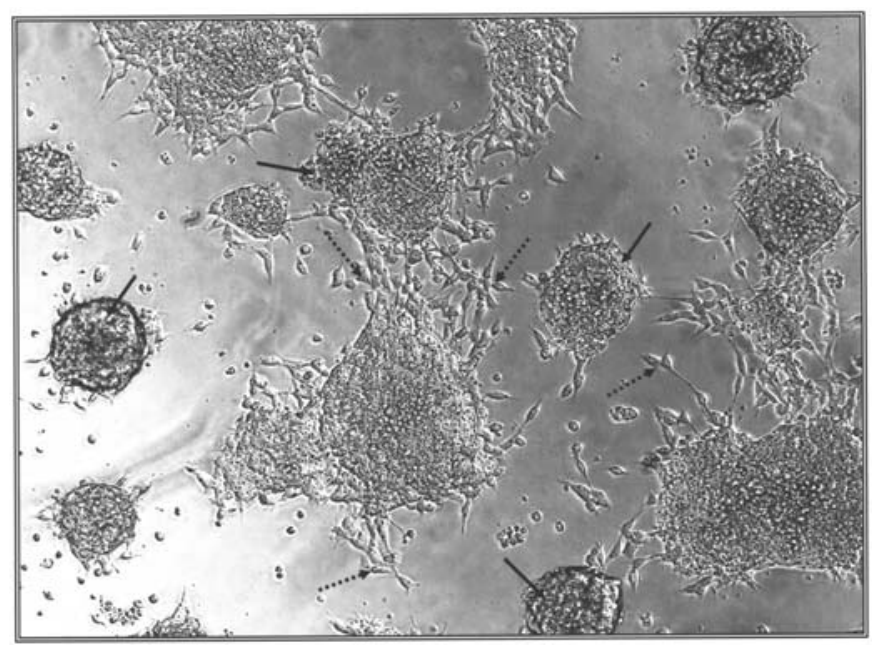

Figure 1. Morphological aspect of the cultured IMR-32 cell lineage. Cells displayed two morphologically distinct types. Small neuroblastoid rounded agregated cells (N-type cells, full arrows) were predominant compared to large hyaline and flattened adherent fibroblastoid cells (S-type cells, dotted arrows) (magnification $\mathrm{x} 200$ ).

dimensions were $818 \times 12 \times 0.175 \mathrm{~mm}$ with two $50 \mathrm{~mm}$ V-shaped ends. The measured total void volume (channel volume + connecting tubing + injection and detection device) was $1857.50 \pm 6.00 \mu 1(\mathrm{n}=6)$. Void volume was calculated after injection and elution time determination of an unretained compound $(0.10 \mathrm{~g} / \mathrm{l}$ of benzoic acid, UV detection at $254 \mathrm{~nm})$. The channel rotor axis distance was measured at $\mathrm{r}=14.82 \mathrm{~cm}$. A Waters 590 programmable HPLC pump (Waters Associates, Milford, MA, USA) was used to pump the sterile mobile phase. The elution signal was recorded at $254 \mathrm{~nm}$ by means of a M1111 (100 mV input) acquisition device (Keithley, Metrabyte, Tauton, MA, USA) operated at $4 \mathrm{~Hz}$ and connected to a Macintosh computer. The optimal elution conditions ('Hyperlayer' mode) were determined experimentally and were: flow injection through the accumulation wall of $100 \mu \mathrm{l}$ of IMR-32 cell suspension $\left(2.5 \times 10^{6}\right.$ cells $\left./ \mathrm{ml}\right)$; flow rate, $0.80 \mathrm{ml} / \mathrm{min}$; mobile phase, sterile PBS; pH 7.4 (Gibco-BRL); external multi-gravitational field strength, $10.00 \pm 0.01 \mathrm{x} \mathrm{g}$ and spectrophotometer detection at $\lambda=254 \mathrm{~nm}$ (Waters 486 Tunable Absorbance Detector, Waters Associates).

For this device, sedimentation fields were expressed in units of gravity, $1 \mathrm{~g}=980 \mathrm{~cm} / \mathrm{s}^{2}$, and calculated as previously described (48). A M71B4 Carpanelli engine associated with a pilot unit Mininvert 370 (Richard Systems, Les Ullis, France), controlled the rotating speed of the centrifuge basket. Sample injections were done by means of a Rheodyne ${ }^{\circledR} 7125$ i chromatographic injector (Rheodyne, Cotati, CA, USA). Cleaning and decontamination procedures have been described in a previous report (28).

For this population, fractions were collected and designated as follow: TP, the total peak; and PF, peak fractions. For cell sorting, 4 fractions were collected: TP, (3'20" to 10'05") and PF1, (3'20" to $\left.4^{\prime} 25^{\prime \prime}\right)$; PF2, (5'00" to 6'45"); and PF3, $\left(7^{\prime} 20^{\prime \prime}\right.$ to $\left.10^{\prime} 05^{\prime \prime}\right)$. To obtain a sufficient quantity of cells for cultures, immunofluorescence assays, BrdU incorporation analyses, successive SdFFF cumulative fraction collections were performed (3 to 10).
Immunofluorescence assays. Control and SdFFF eluted cells $\left(5 \times 10^{5}\right.$ cells/well) were cultured in 8-well Permanox Lab-Tek ${ }^{\circledR}$ plates for 24, 48 and $72 \mathrm{~h}$. Cells were fixed in $4 \%$ paraformaldehyde (PFA, Sigma-Aldrich, Saint Quentin Fallavier, France) in PBS (Gibco-BRL) for $30 \mathrm{~min}$ at room temperature and permeabilized using ethanol/acetone (v/v) (Sigma-Aldrich) for $5 \mathrm{~min}$ at $4^{\circ} \mathrm{C}$. After 2-h saturation with $10 \%$ goat serum (Sigma-Aldrich) in PBS, cells were incubated for 90 min either with mouse anti-neural cell adhesion molecule (N-CAM, NKH-1-RD1, Coulter Beckman, Fullerton, USA) mouse antineurofilament (NF) mAb (2F11, 1/50, Dako, Trappes, France), rabbit anti-glial fibrillary acidic protein mAb (GFAP, 1/50, Dako), mouse anti-polySialylic acid-neural cell adhesion Molecule (PSA-N-CAM) mAb (clone 2-2B, 1/200, Abcys, Paris, France), mouse anti-Fas mAb (B-G27, 1/20, Diaclone, Besançon, France) or rabbit polyclonal anti-nestin (1/20, Santa Cruz Biotechnology, Heidelberg, Germany). Antibodies IgG1 and IgG2a (B-Z1 and B-Z2, Diaclone) or rabbit irrelevant immunoglobulins (Ig, Dako) diluted in saturating buffer were used as isotypic controls. Antibodies were revealed by a 30 -min incubation with Alexa Fluor 488conjugated goat anti-mouse, Alexa Fluor 594-conjugated goat anti-mouse or Alexa Fluor 594-conjugated goat anti-rabbit antibodies $(1 / 9,000$ in PBS, Molecular Probes, Leiden, The Netherlands). Cells were fixed with glycerol gelatin (SigmaAldrich) and examined by fluorescence microscopy (Leica DMRX with a camera DFC 300 FX, Rueil-Malmaison, France).

BrdU incorporation analyses. Control and sorted cells seeded in 8-well Permanox Lab-Tek plates $\left(5 \times 10^{5}\right.$ cells/well) were incubated for 24,48 and $72 \mathrm{~h}$ with $20 \mu \mathrm{M}$ of 5-bromo-2deoxyuridine (BrdU, Sigma). BrdU is a DNA base analogue in which the methyl group of thymidine is replaced with a bromide. BrdU is incorporated into DNA during replication. Consequently, cell labelling is proportional to DNA synthesis during the $\mathrm{S}$ phase. Cells were first fixed in 4\% PFA in PBS for $30 \mathrm{~min}$ at room temperature and permeabilized with ethanol/acetone $(\mathrm{v} / \mathrm{v})$ for $5 \mathrm{~min}$ at $4^{\circ} \mathrm{C}$. DNA was then denatured with $2 \mathrm{M} \mathrm{HCl}$ for $1 \mathrm{~h}$ and $\mathrm{HCl}$ was neutralised with $0.1 \mathrm{M}$ boric acid, $\mathrm{pH} 8.2$ for $10 \mathrm{~min}$. After washes in $\mathrm{PBS}$, cells were incubated with mouse anti-BrdU $\mathrm{mAb}$ (Sigma) diluted at $1 / 100$ in PBS at room temperature, for 90 min followed by a 30-min incubation with Alexa Fluor 488conjugated goat anti-mouse (diluted 1/9,000 in PBS, Molecular Probes). Cells were stained with Evans Blue dye (Sigma-Aldrich) for $10 \mathrm{~min}$ in order to visualize all cells (red fluorescence). After washes in PBS, cells were fixed with glycerol gelatin (Sigma-Aldrich) and examined by fluorescence microscopy.

\section{Results}

Characterization of the IMR-32 cell lineage by immunocytofluorescent assays. As shown in Fig. 1, cultured IMR-32 cells displayed two morphologically distinct types. The small neuroblast-like cell population, N-type cells (Fig. 1, full arrows) was the predominant one and grew as poorly adherent aggregates. The cell population of large hyaline fibroblast-like cells, S-type (Fig. 1, dotted arrows), was a minor component. Cells were flat and adherent to substrate. 

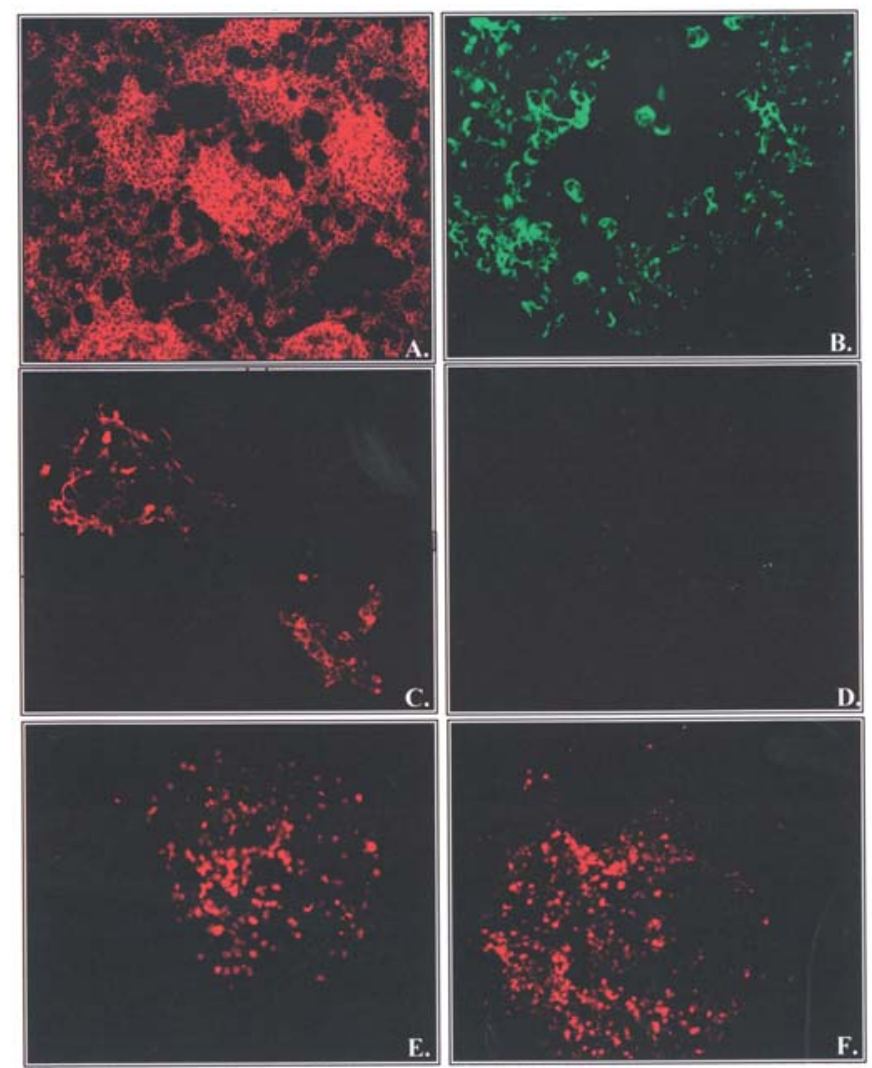

Figure 2. Immunological characterization of IMR-32 cell lineage. Expression of N-CAM (A), neurofilament (B), PSA-N-CAM (C), GFAP (D), Fas (E) and nestin $(\mathrm{F})$ in the total IMR-32 cell population. Cell labeling was done on IMR-32 neuroblastoma cell line using Alexa Fluor 488 (green, B) and 594 (red, A, C-F) secondary antibodies (magnification x200 for A, B, D and magnification $\mathrm{x} 400$ for $\mathrm{C}, \mathrm{E}$ and $\mathrm{F}$ ).

Eirst, neural origin of IMR-32 cells was confirmed by immunocytochemistry. These studies performed on the total IMR-32 cell population (Fig. 2), showed that S-type cells expressed the Neural-Cell Adhesion Molecule (N-CAM, Fig. 2A) and the neurofilament protein (Fig. 2B, NF) whereas $\mathrm{N}$-type cells did not express these markers. At the periphery of the aggregates, cells expressed the polysialylated form of the Neural Cell Adhesion Molecule (PSA-N-CAM, Fig. 2C) which characterizes early differentiating post-mitotic neurons.

IMR-32 cells were not stained by anti-glial fibrillary acidic protein (GFAP, Fig. 2D). This result confirmed that no astrocytic cells were present in this cell line.

Neuroblastoid aggregated cells expressed Fas protein (Fig. 2E, CD95) on their membrane and highly expressed an antigenically primitive protein, nestin (Fig. 2F).

SdFFF elution and fraction collection. Fig. 3 displays a characteristic fractogram of IMR-32 cells. Two peaks were observed, the first corresponding to the void volume peak $\left[\mathrm{R}_{\mathrm{obs}} \approx 1\right.$, retention ratio $\mathrm{R}_{\mathrm{obs}}=$ void time versus retention time $\left.=\mathrm{t}_{0} / \mathrm{t}_{\mathrm{R}}(25)\right]$, and the second corresponding to the cellular species with $\mathrm{R}_{\mathrm{obs}}=0.430 \pm 0.024(\mathrm{n}=6)$. As previously described $(53,54)$, the absolute $\mathrm{R}_{\mathrm{obs}}$ value depends on culture conditions and number of cell passages which should range

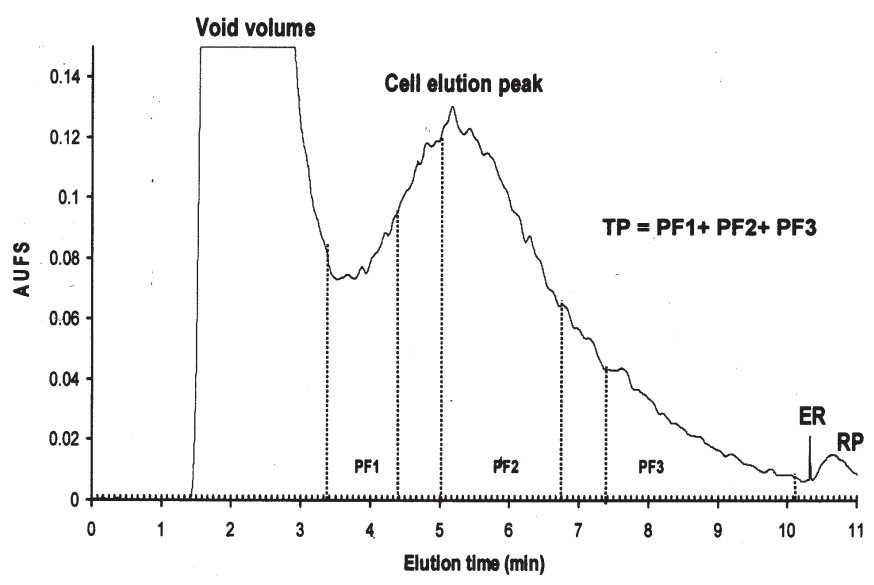

Figure 3. Representative fractogram of IMR-32 cells after SdFFF elution. Elution conditions: flow injection of $100 \mu 1$ cell suspension $\left(2.5 .10^{6}\right.$ cells $\left./ \mathrm{ml}\right)$; flow rate, $0.80 \mathrm{ml} / \mathrm{min}$; and external multi-gravitational field, $10.00 \pm 0.03 \mathrm{~g}$; spectrophotometric detection at $\lambda=254 \mathrm{~nm}$. ER corresponds to the end of channel rotation: at this moment, the mean externally applied field strength is equal to zero gravity, thus RP, a residual signal, corresponds to release peak of reversible cell-accumulation wall sticking. Fraction collection: TP, (3'20" to $\left.10^{\prime} 05^{\prime \prime}\right)$; and PF1, (3'20" to $\left.4^{\prime} 25^{\prime \prime}\right)$; PF2, (5'00" to 6'45"; and PF3, (7'20" to $\left.10^{\prime} 05^{\prime \prime}\right)$.

from 4 to 10 for these cells. At constant flow rate $(0.80 \mathrm{ml} / \mathrm{min})$, according to the 'Hyperlayer' elution mode description, the $R_{\text {obs }}$ value is field dependent: $R_{\text {obs }}=0.471 \pm 0.012(n=3)$ at $8.00 \mathrm{~g}$ and $\mathrm{R}_{\mathrm{obs}}=0.381 \pm 0.024(\mathrm{n}=3)$ at $12.00 \mathrm{~g}$. By using the following equation $(26,49)$,

$$
R=\frac{6 s}{\omega}
$$

in which $\mathrm{R}$ is the retention ratio, $\omega$ is the channel thickness $(175 \mu \mathrm{m})$, and $\mathrm{s}$ the distance from the center of the focused zone to the channel wall (26), we calculated the approximate average cell elevation (s) using $\mathrm{R}_{\mathrm{obs}}$ values: $\mathrm{s}=12.54 \mu \mathrm{m}$. The mean cell diameter was $10.50 \pm 0.84 \mu \mathrm{m}\left(\mathrm{n}=6\right.$, Coulter Counter $\left.^{\circledR}\right)$. Thus, cell radii were less than the approximate average cell elevation value: $\mathrm{r}=5.25<\mathrm{s}=12.54 \mu \mathrm{m}$. Finally, after total cell elution, when the external field was turned off (mean external field $=0.00 \mathrm{x} \mathrm{g}$ ), we observed a residual signal (Fig. 3, RP) corresponding to the reversible particle release from the accumulation wall.

As shown in Fig. 3, four cell fractions were collected: i) the total peak fraction (TP) which corresponded to the total IMR-32 population eluted; and ii) peak fractions 1, 2 and 3 $\left(\mathrm{PF}_{\mathrm{n}}\right)$ which were time-dependent collected fractions of the retained peak profile ('cell elution peak' in Fig. 3).

Cellular kinetics of the IMR-32 cell line. A kinetic study of fractions seeded for 24, 48 and $72 \mathrm{~h}$ was performed. Cultures, as well as immunological and proliferation studies were conducted both on SdFFF eluted fractions and on a control IMR-32 population in order to: i) determine if it was possible to obtain fractions enriched in $\mathrm{N}$ - or S-type subpopulations, ii) to determine whether these cells could be defined (state of differentiation) and iii) establish the relationship between 


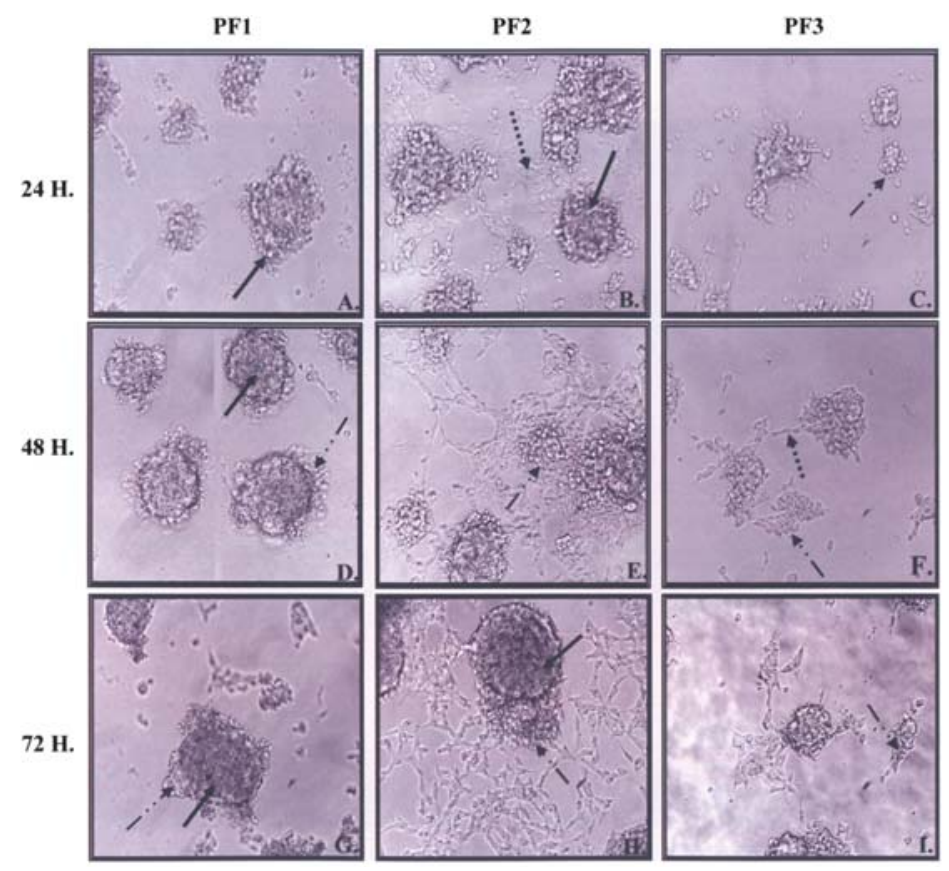

Figure 4. Kinetics of morphological changes in IMR-32 eluted fractions (PF1, PF2 and PF3). Cellular morphology was observed on SdFFF sorted cells seeded for 24, 48 and $72 \mathrm{~h}$. Differences were seen according to fractions: N-type aggregated cells (full arrows), S-type adherent cells (dotted arrows) and less dense $\mathrm{N}$-type aggregates (broken arrows) (magnification $\mathrm{x} 400$ ).
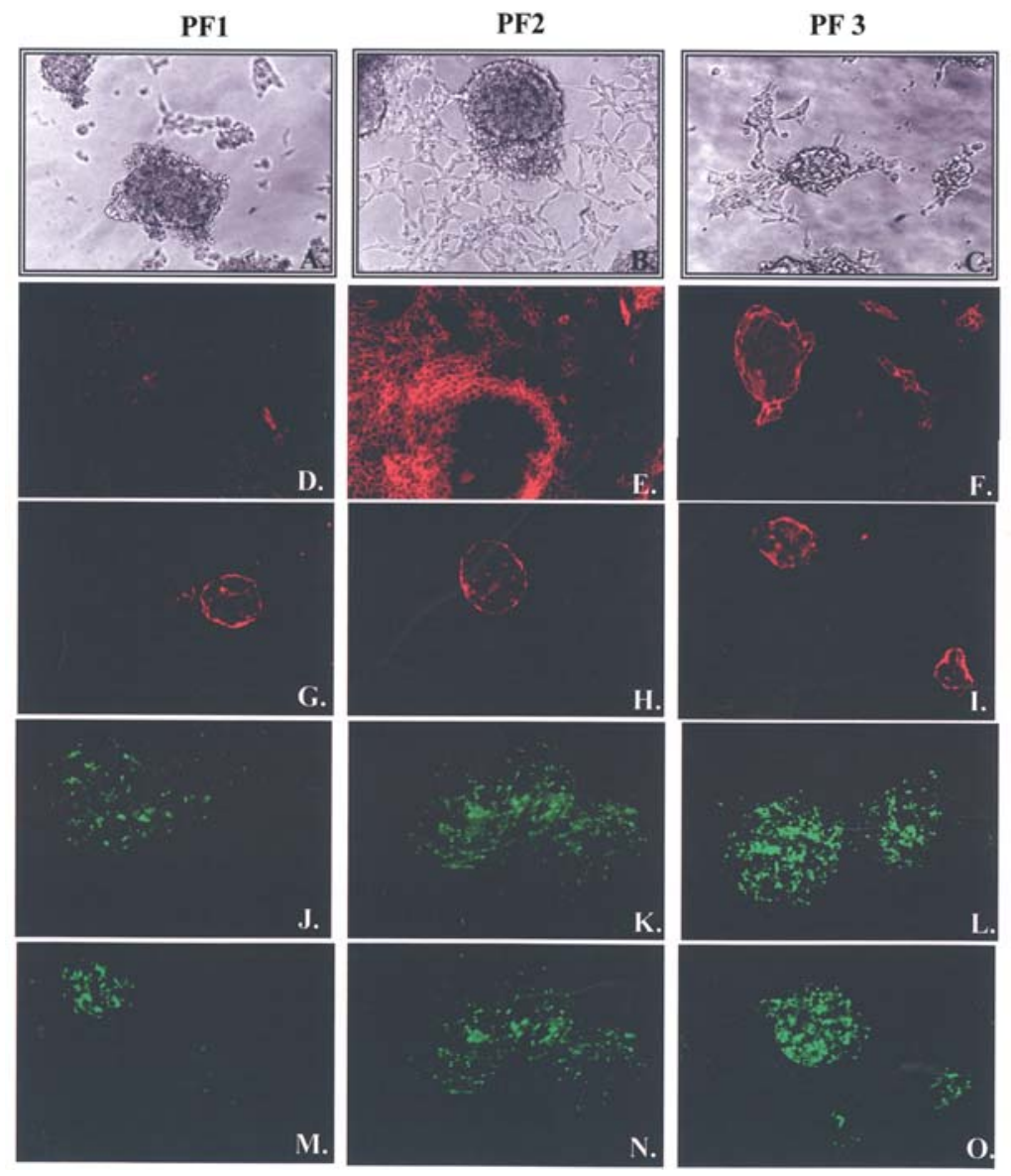

Figure 5. Immunological characterization of IMR-32 eluted fractions (PF1, PF2 and PF3) after 72-h culture. (A-C), contrast phase optical microscopy; (D-F), N-CAM; (G-I), PSA-NCAM; (J-L), Fas; and (M-O), nestin expressions. Cell labelling was done using Alexa Fluor 488 (green fluorescence) and 594 (red fluorecence) secondary antibodies (magnification $\mathrm{x} 400$ ).

the different isolated phenotypes.

Contrast phase microscopy of eluted fractions. Optical micro- scopy observations of these cultures showed that fractions were composed of different cell types and behaved differently 

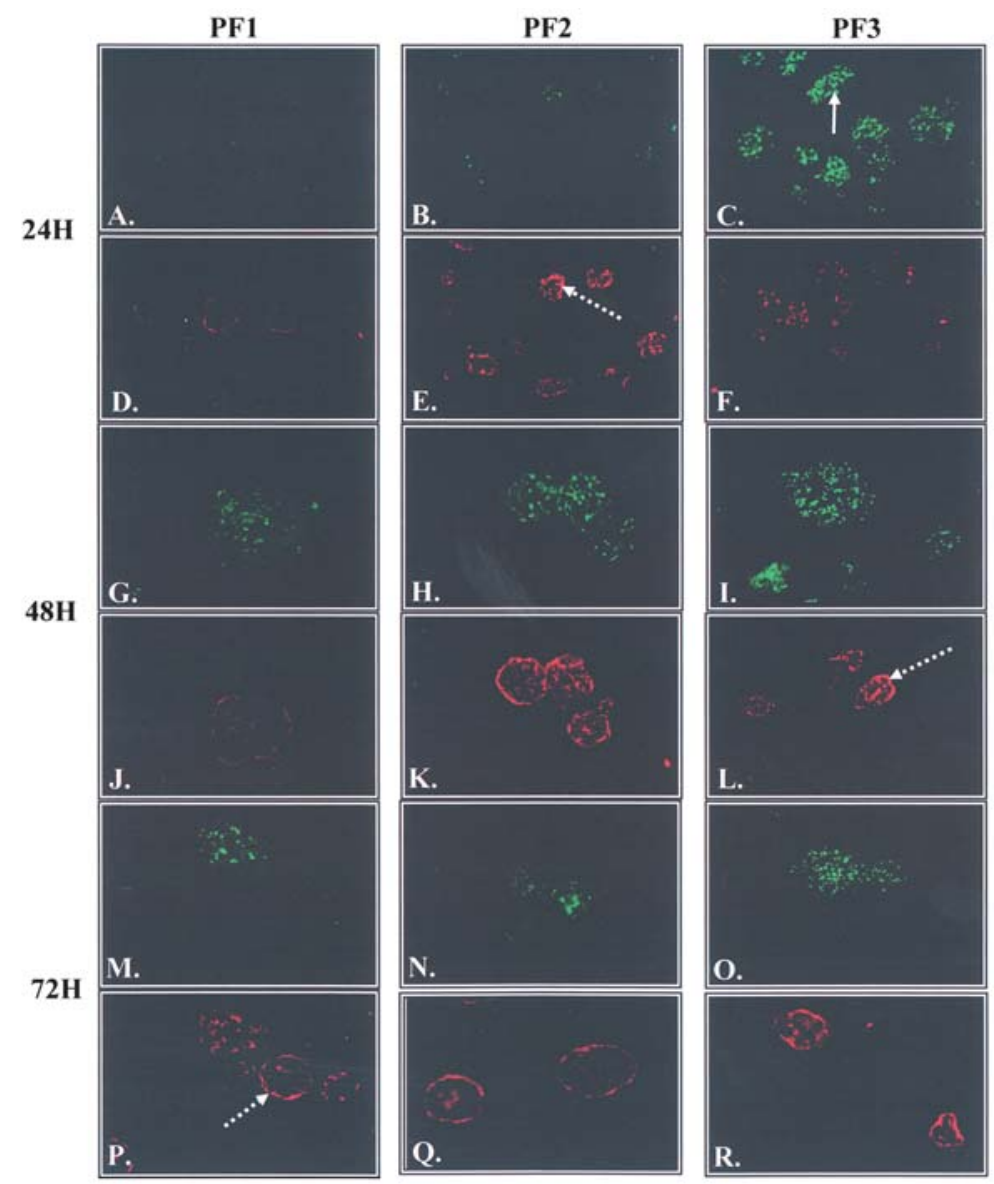

Figure 6. Kinetics of nestin and PSA-NCAM expression in the IMR-32 eluted fractions (PF1, PF2 and PF3) after 24, 48 and 72-h in culture. Alexa Fluor 488 was used for the study of nestin expression (A-C, G-I, M-O): full arrows, cells contained in the aggregates. Alexa Fluor 594 was used for the study of PSANCAM expression (D-F, J-L, P-R): dotted arrows, at the periphery of the aggregates (magnification $\mathrm{x} 400$ ).
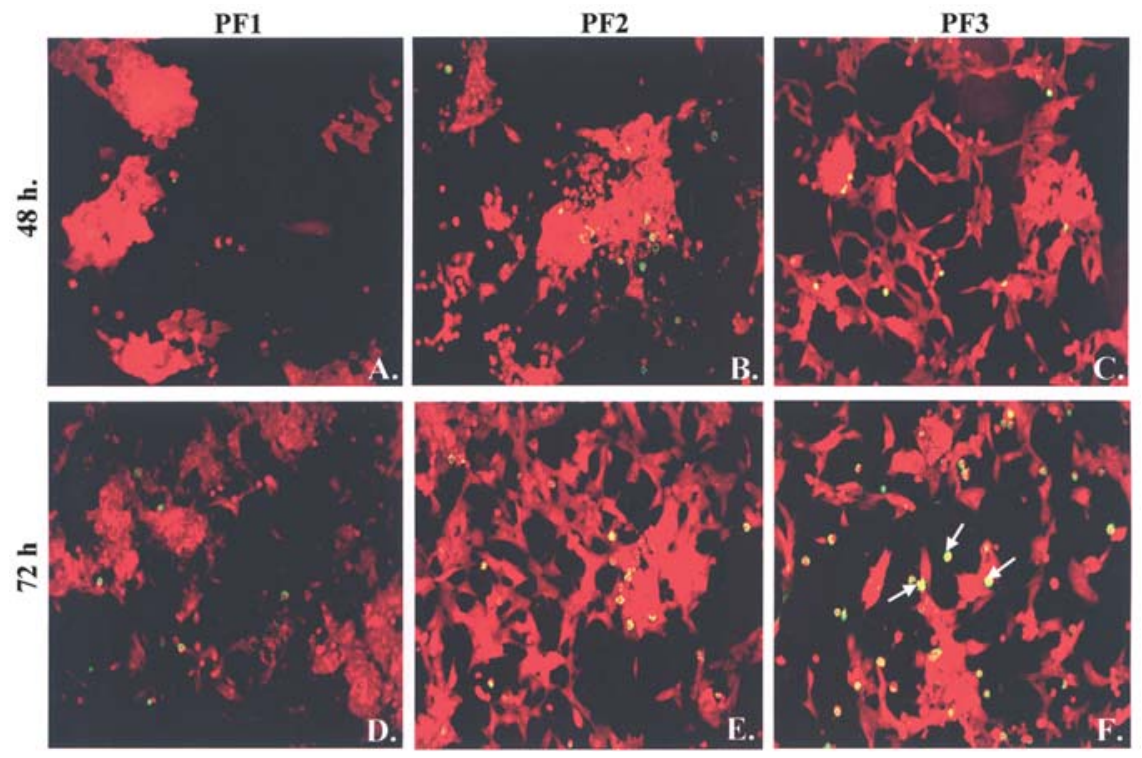

Figure 7. BrdU incorporation in the IMR-32 eluted fractions (PF1, PF2 and PF3) after 48 and 72-h culture. Evans blue dye (red fluorescence) was used for labelling of all cells and Alexa Fluor 488 (green fluorescence) was directed against anti-BrdU: full arrows, round cells (magnification x200).

over time (Fig. 4).

In PF2, cells behaved similarly to control IMR-32 and to TP fractions as early as after $24 \mathrm{~h}$ of culture (Fig. 4B) with two cell phenotypes: N-type aggregated cells (Fig. 4, full arrows) and S-type flattened adherent cells (Fig. 4, dotted arrows). After 48-h culture, we observed less dense round cells resembling those sorting in PF1 (Fig. 4E, broken arrows) and S-type cells with increased cell number over time (Fig. 4E and H). From a morphological point of view, 3 cellular phenotypes were distinguished in PF2 after 72-h culture: N-type cells 
massed in dense aggregates (full arrows), adherent S-type cells (dotted arrows) and intermediate cells at the periphery of the aggregates (broken arrows).

At $24 \mathrm{~h}, \mathrm{PF} 1$ was composed of large and dense aggregates of round cells (Fig. 4A, full arrows). These aggregates persisted without the apparition of adherent cells during $72 \mathrm{~h}$ and became denser over time (Fig. 4D-G). At the periphery of these aggregates, we observed less dense round cells which were progressively (at 48 and $72 \mathrm{~h}$ ) separated from aggregates (Fig. 4D and G, broken arrows).

In the third eluted fraction PF3, N-type cells were sorted and early organized into aggregates. After 24-h culture, these aggregates looked smaller and less dense (Fig. 4C) than those sorted in PF1 (Fig. 4A) or in PF2 (Fig. 4B). These cells exhibited similar morphological features to those observed at the periphery of the large aggregates sorted in PF1 and in PF2 (Fig. 4, broken arrows). In PF3, adherent cells appeared only after 48-h culture (Fig. 5F, dotted arrows) and seemed to spring from the neuroblastoid aggregates.

Characterization of IMR-32 eluted fractions after 72-h culture. PF2 (Fig. 5B) showed a similar morphology to the cell population and the total peak fraction. Markers were similar to those observed in the IMR-32 cell line (Fig. 2): i) N-CAM in adherent cells (Fig. 5E); ii) PSA-N-CAM for cells at the periphery of the aggregates (Fig. 5H); iii) Fas expressed in round cells (Fig. 5K); and iv) nestin also expressed in these $\mathrm{N}$-type cells (Fig. 5N). Cells in PF2 expressed more Fas and nestin than those sorted in PF1.

In PF1, large and dense aggregates of cells weakly expressed Fas and nestin (Fig. 5J and M) and PSA-N-CAM labelling was observed in cells at the periphery of these aggregates (Fig. 5G). In this fraction, there were no adherent cells (Fig. 5A) and no N-CAM labelling (Fig. 5D).

In PF3, cells grouped in small aggregates strongly expressed fas and nestin (Fig. 5L and O). This labelling was more intense than staining observed in PF1 (Fig. 5J and M) or in PF2 (Fig. 5K and N). Morphological observations (Fig. 5C) showed many adherent S-type cells which expressed N-CAM (Fig. 5F) but this labelling was very weak in comparison to labelling in PF2 in which there were more adherent cells. Cells around the aggregates expressed PSA-N-CAM (Fig. 5I) and this labelling seemed to be more intense than in PF1 or in PF2.

As we observed differences of labelling between fractions, we thoroughly examined PSA-N-CAM and nestin expression as a function of culture time and fraction.

Kinetics of PSA-N-CAM and nestin expression and incorporation of BrdU in eluted fractions. In order to better understand the relationship which exists between these different cellular phenotypes, expression of nestin and PSA-N-CAM was studied on the three eluted cell fractions cultured for 24, 48 and 72 h (Fig. 6). Nestin was highly expressed by neuroblastoid cells in small aggregates sorted in PF3 as early as 24-h culture (Fig. 6C, full arrows). This labelling persisted for $72 \mathrm{~h}$ (Fig. 6I and O) while it slightly appeared in PF1 (Fig. 6G) and in PF2 (Fig. 6H) only after 48-h culture. N-type cells sorted in PF1 and in PF3 did not similarly express nestin.

Cells at the periphery of aggregates strongly expressed PSA-N-CAM after 24-h culture only in PF2 ( Fig. 6E, dotted arrows) and this labelling was intensified at $48 \mathrm{~h}$. This staining only appeared in PF3 after 48-h culture (Fig. 6L, dotted arrows) and was weakly observed after 72-h culture in PF1 (Fig. 6P, dotted arrows).

BrdU incorporation in these fractions was assessed in order to study the proliferative potential of these cells (Fig. 7). Green fluorescence, corresponding to incorporated BrdU in cells, is proportional to DNA synthesis. Only N-type cells incorporated BrdU and only after 48-h culture. Cells sorted in PF3 seemed to proliferate more than cells sorted in PF1 or in PF2 and this labelling was more intense after 72-h culture. N-type cells in dense aggregates sorted in PF1 seemed to be in a quiescent state. In contrast, round cells on the periphery of the aggregates were highly proliferative and cells were mostly sorted in PF3 (Fig. 7F). Thus, N-type cells sorted in PF1 and in PF3 did not have the same characteristics of cell division or PSA-N-CAM and nestin expression and may correspond to two different $\mathrm{N}$-phenotypes. These results were correlated with morphological observations.

\section{Discussion}

Most neuroblastomas are undifferentiated malignant tumors derived from neural crest precursors that are capable of differentiating into a variety of cells, including neurons, melanocytes or Schwann cells. The neoplastic population in $\mathrm{NB}$ is extremely heterogeneous and cells are highly variable in their state of differentiation. This heterogeneity, observed in cell lines, could affect treatment. The goal of this study was to understand the relationship which exists between these different cellular phenotypes by using SdFFF cell sorting in order to ultimately improve response and NB patient outcome. The IMR-32 cell lineage was chosen for this study because of its cellular heterogeneity: N-type and S-type cells (Fig. 1). The immunological characterization of the IMR-32 cell lineage confirmed its heterogeneity and its neural origin (Fig. 2). First, S-type cells expressed markers of mature neurons. These results could correlate with the stage of differentiation as suggested by N-CAM and neurofilament expression which is associated with adhesion of neurons after migration (55). By mediating cell adhesion and signal transduction, N-CAM is associated with neuritis outgrowth and fasciculation of several axonal expansions which are correlated with neuron maturation (56). N-type cells expressed nestin, a marker of multipotent neuroectodermal precursor cells (1). This protein is expressed in a cell-cycle-dependent manner and is downregulated as neuroepithelial stem cells cease division and differentiation along their respective neural or glial lineages (1). Similar to N-Myc, tumor aggressiveness has been associated with elevated nestin levels in some tumors (3). For instance, in primitive neuroectodermal tumors, elevated nestin expression characterizes the most malignant cell type (57). Also, nestin protein is elevated in the infiltrating parts of highly metastatic human glioblastomas and astrocytomas and has been proposed to play a role in tumor invasion in melanomas (57). These neuroblastoid cells also expressed the Fas receptor which is known to induce apoptosis in many cell types when activated by its natural ligand (FasL) $(50,58,59)$ or by an agonist antibody. The expression of Fas by some tumor cells such as a neuroblastoma or glioblastoma cell line is known $(50,59)$. This membrane protein is also expressed by 
normal neurons especially motor neurons (49). Fas was reported to be expressed transiently by neuroblasts in the differentiating rat cortex in situ and even more after culture (60) but the pattern of Fas expression during neuronal differentiation is still unknown.

At the periphery of the aggregates, round cells appeared to be in an intermediate state of differentiation and expressed PSA-N-CAM. Evidence from in vitro models has implicated polysialylation in the regulation of cell growth, migration, and differentiation (61). Polysialic acid (PSA) is a regulatory epitope of neural cell adhesion molecule (NCAM) in homophilic adhesion of neural cells mediated by NCAM. It is also known to be re-expressed in several human tumors and serves as an onco-developmental antigen (62).

Altogether these markers suggest that these cell types correspond to different states of differentiation: immature cells $\left(\right.$ nestin $\left.{ }^{+}, \mathrm{Fas}^{+}\right)$, differentiate cells $\left(\mathrm{N}-\mathrm{CAM}^{+}, \mathrm{NF}^{+}\right)$and cells in an intermediate state of differentiation (PSA-N-CAM ${ }^{+}$). Therefore, the IMR-32 cell line could be used as a very good model for the understanding of mechanisms which link NB cell phenotypes.

Since the report of Caldwell et al (16), the SdFFF elution mode of cellular species is described as 'Hyperlayer' $(15,16,18,24,28,48)$. In the 'Hyperlayer' mode, the flow velocity/channel thickness balance generates hydrodynamic lift forces which focus cells into a thin layer (equilibrium position) away from the accumulation wall. At equilibrium position, the external field is exactly balanced by the hydrodynamic lift forces (15-19,21-26). Under 'Hyperlayer' mode, the sample will not be eluted when in close contact with the accumulation wall reducing the risk of cell-wall interactions and providing better cell separation $(10,15-19,21-26,28)$. The approximate average cell elevations should be greater than the particle radius. As described previously $(15-19,21-23,25,26)$, the 'Hyperlayer' elution mode predicts a size/density dependent cell elution order. At equivalent density, large particles generate more lift force and are focused in faster streamlines to be eluted first. On the other hand, exerted gravitational forces increase with particle density. Denser particles are focused near the accumulation wall to be eluted last. Moreover, cell shape and rigidity influence cell elution order (24). The different average velocities, and the retention order of different species are compared by means of the observed retention ratio $R_{\text {obs }}(25)$. Under the 'Hyperlayer' elution mode, retention ratio $\mathrm{R}_{\mathrm{obs}}$ is flow rate and external field dependent. At constant field, the increase in flow rate induces an increase in $\mathrm{R}_{\mathrm{obs}}$, and at constant flow the increase in field decreases $R_{\text {obs. }}$. If the external field can be increased sufficiently, or flow rate decreased sufficiently to offset the lift force, cells are confined in a very thin layer close to the accumulation wall. This elution mode is described as 'Steric' (15-19,21-26) and appears as a limit case of 'Hyperlayer'. By driving species close to the accumulation wall, the 'Steric' elution mode enhances cell/channel wall interactions which lead to channel poisoning with harmful consequences on cell integrity, viability and recovery. Actually, cell/channel wall interactions could induce cell differentiation and/or cell death which is highly undesirable in the study of cellular processes such as population dynamics.

'Hyperlayer' elution mode allowed, by drastic limitation of cell-accumulation wall interactions, a cell elution which: i) respected repeatability, reproducibility and recovery; ii) respected cell functional integrity; iii) provided high levels of short- and long-term viability (no apoptosis induction); iv) respected the maturation and differentiation stages; and finally v) enhanced better sub-population sorting and characterization (28). In association with specific cleaning and decontamination procedures (28), the device setup (polystyrene channel walls, flow sample injection through the accumulation wall) and elution conditions (see 'Materials and methods') were optimized to promote this safety elution mode.

Then, according to the 'Hyperlayer' elution mode description (15-19,21-26): particle elution away from the accumulation wall ( $\mathrm{s}>\mathrm{r}$ ), field or flow dependence of the $\mathrm{R}_{\mathrm{obs}}$ value and the limited interactions between cells and accumulation wall leading to low reversible cellular release (Fig. 3, RP); we can assume that IMR-32 cells were eluted under 'Hyperlayer' elution mode as it has been demonstrated for other cell models $(11,38,48,49,51-54)$.

The use of these optimal elution conditions should allow better cell sub-population separation respecting functional integrity, viability, sterility, maturation stage and differentiation processes. However, it was not established if cell sorting of the different IMR-32 sub-populations was achieved, and in particular, if we were able to sort $\mathrm{N}$-type cells from the $\mathrm{S}$ ones (Fig. 1). As shown in Fig. 3, four cell fractions were collected: i) the total peak fraction (TP) which corresponded to the total IMR-32 population eluted; and ii) peak fractions 1,2 and $3\left(\mathrm{PF}_{\mathrm{n}}\right)$ which are the time-dependent collected fractions of the retained peak profile. Cell culture, proliferation and specific antigen expression studies were conducted as a function of cellular fraction and culture time in order to: i) establish the cellular relationship between the different subpopulations; and ii) to propose kinetics of the differentiation process concerning the IMR-32 cell line.

The results showed that cells behaved differently over time, according to sorted fractions. In PF2, cells looked like the total IMR-32 population as early as $24 \mathrm{~h}$ after culture. BrdU incorporation studies showed that only few cells proliferated in this fraction after 72-h culture and that only $\mathrm{N}$-type cells divided. Markers and intensity of labelling were similar to those observed in the total IMR-32 population (Figs. 2 and 5): N-type cells expressed potential oncological markers related to the immature state of tumoral cells (nestin and fas) and adherent S-type cells expressed markers normally seen in mature neuronal cells (N-CAM). Cells located at the periphery of the aggregates strongly expressed PSA-N-CAM (Fig. 6), $48 \mathrm{~h}$ after culture. We hypothesized that these cells, in an intermediate state of differentiation, pursued their differentiation and became S-type cells. Between 24 and $48 \mathrm{~h}$ some cells in large and dense aggregates expressed nestin (Fig. 6H). Some cells which were detached from aggregates (Fig. 4E) intensively expressed PSA-N-CAM (Fig. 6K) and became adherent S-type cells.

This hypothesis was confirmed by the use of SdFFF. In PF3, after SdFFF elution, we obtained a majority of N-type cells which were organized in less dense and smaller aggregates than those sorted in PF2. BrdU incorporation (Fig. 7) showed that cells in this fraction had a better proliferative potential than cells sorted in PF2. Only round cells located at the periphery of the aggregates seemed to have the capacity for 
division. In aggregates, cells expressed nestin as early as 24-h in culture (Fig. 6) and the fluorescence intensity was higher than those sorted in PF2. It seems that we obtained a fraction enriched with these immature cells able to proliferate and also differentiate into adherent cells. At the periphery of the aggregates cells expressed PSA-N-CAM (Fig. 6) after 48-h culture and adherent cells detached from these masses (Fig. 5). These cells expressed N-CAM (Fig. 4) after 72-h culture. These results showed the dynamism of the cell population and confirmed that differentiated S-type cells derived from aggregates.

In PF1, N-type cells were sorted and then organized into large dense aggregates which persisted in time without the apparition of adherent cells. BrdU incorporation studies showed that these cells should have a minor proliferative potential (Fig. 7) and seemed to be in a quiescent state. We hypothesized that they constitute another state of differentiation with slight expression of precursor markers: nestin and fas (Figs. 4 and 6). Some cells expressed PSA-N-CAM at the periphery of the aggregates (Figs. 4 and 6) after 72-h culture. Perhaps these cells need other cell types, N-type cells sorted in PF3 or/and S-type cells, to continue their cycle.

In conclusion, the association of SdFFF cell separation with specific cell characterization tools resulted in the isolation of different cell phenotypes present in the IMR-32 lineage and the understanding of the IMR-32 cell population dynamism. We demonstrated that SdFFF was able to sort $2 \mathrm{~N}$-phenotypes. The first N-phenotype (sorted in PF1) formed a pool of quiescent cells. First hypothesis was that these cells were in a quiescent state because they needed other cell phenotypes to create the IMR-32 cell lineage. We also hypothesized that these cells could produce the second type (N-type cells sorted in PF3), able to proliferate and to differentiate into adherent S-type cells. These results suggested a close interaction between these different cell phenotypes. N-type cells sorted in PF3 have characteristics of malignant cells (high expression of nestin) and they also have a great potential for differentiation. These cells express PSA-N-CAM which could play a role in the metastatic properties of these cells and transform into S-type cells.

Over the last few years, we examined the different applications of SdFFF cell elution and sorting in cancer research. These results demonstrated for the first time, the capacity of this simple, fast, gentle and non-invasive method to sort cell phenotypes and to understand their differentiation kinetics and relationships.

Finally, we hypothesize that these different phenotypes would react differently to stimulations with differentiation or apoptosis inducers. It would be of great interest to study the effects of several drugs on undifferentiated cells and the two sorted N-phenotypes to characterize some differences in response to the same molecule.

\section{Acknowledgements}

Authors are grateful to Dr J. Cook-Moreau for corrections in the preparation of this manuscript. The expenses of this work were defrayed in part by the Ministère de l'Education Nationale, de la Recherche et de la Technologie, the Conseil Régional du Limousin and by the Ligue contre le Cancer (Comités de la Corrèze et de la Haute-Vienne).

\section{References}

1. Abemayor E and Sidell N: Human neuroblastoma cell lines as models for the in vitro study of neoplastic and neuronal cell differentiation. Environ Health Perspect 80: 3-15, 1989.

2. Morgenstern BZ, Krivoshik AP, Rodriguez V and Anderson PM: Wilms' tumor and neuroblastoma. Acta Paediatr Suppl 93: 78-85, 2004.

3. Brodeur GM, Seeger RC, Schwab M, Varmus HE and Bishop JM: Amplification of N-myc in untreated human neuroblastomas correlates with advanced disease stage. Science 224: 1121-1124, 1984.

4. Schwab M, Ellison J, Busch M, Rosenau W, Varmus HE and Bishop JM: Enhanced expression of the human gene N-myc consequent to amplification of DNA may contribute to malignant progression of neuroblastoma. Proc Natl Acad Sci USA 81: 4940-4944, 1984.

5. Berthold F, Hero B, Kremens B, et al: Long-term results and risk profiles of patients in five consecutive trials (1979-1997) with stage 4 neuroblastoma over 1 year of age. Cancer Lett 197: $11-17,2003$

6. De Bernardi B, Nicolas B, Boni L, et al: Disseminated neuroblastoma in children older than one year at diagnosis: comparable results with three consecutive high-dose protocols adopted by the Italian Co-Operative Group for Neuroblastoma. J Clin Oncol 21: 1592-1601, 2003.

7. Hopkins-Donaldson S, Yan P, Bourloud KB, Muhlethaler A, Bodmer JL and Gross N: Doxorubicin-induced death in neuroblastoma does not involve death receptors in S-type cells and is caspase-independent in N-type cells. Oncogene 21: 6132-6137, 2002.

8. Voigt A, Hartmann P and Zintl F: Differentiation, proliferation and adhesion of human neuroblastoma cells after treatment with retinoic acid. Cell Adhes Commun 7: 423-440, 2000.

9. Cardot PJP, Battu S, Chianea T and Rasouli S: Cells and cell organelles: field-flow fractionation. In: Encyclopedia of Separation Science. Wilson ID, Adlard ER, Cooke M and Poole CF (eds). Academic Press, London, pp2267-2271, 2000.

10. Cardot PJP, Chianea T and Battu S: Sedimentation field flow fractionation of living cells. In: Encyclopedia of Chromatography. Cazes J (ed). M. Dekker Inc., New York, pp742-747, 2001 .

11. Chianea T, Assidjo NE and Cardot PJP: Sedimentation fieldflow-fractionation: emergence of a new cell separation methodology. Talanta 51: 835-847, 2000.

12. Bauer J: Advances in cell separation: recent developments in counterflow centrifugal elutriation and continuous flow cell separation. J Chromatogr B 722: 755-769, 1999.

13. Levin S: Field flow fractionation in biomedical analysis. Biomed Chromatogr 5: 133-137, 1991.

14. Wang XB, Yang J, Huang Y, Vykoukal J, Becker FF and Gascoyne PR: Cell separation by dielectrophoretic field-flowfractionation. Anal Chem 72: 832-839, 2000.

15. Caldwell KD: Steric field-flow fractionation and steric transition. In: Field-Flow Fractionation Handbook. Schimpf ME, Caldwell KD and Giddings JC (eds). John Wiley \& Sons, Inc., New York, pp 79-94, 2000.

16. Caldwell KD, Cheng ZQ, Hradecky P and Giddings JC: Separation of human and animal cells by steric field-flow fractionation. Cell Biophys 6: 233-251, 1984.

17. Caldwell KD, Nguyen TT, Murray TM, Myers MN and Giddings JC: Observations on anomalous retention in steric fieldflow fractionation. Sep Sci Technol 14: 935-946, 1979.

18. Giddings JC: Field-flow fractionation: analysis of macromolecular, colloidal and particulate materials. Science 260: 1456-1465, 1993.

19. Giddings JC: The field-flow fractionation family: underlying principles. In: Field-Flow Fractionation Handbook. Schimpf ME, Caldwell K and Giddings JC (eds). John Wiley \& Sons, Inc., New York, pp3-30, 2000.

20. Latham AH, Freitas RS, Schiffer P and Williams ME: Capillary magnetic field flow fractionation and analysis of magnetic nanoparticles. Abstracts of Papers, 230th ACS National Meeting, Washington, DC, 77: 5055-5062, 2005.

21. Martin M and Williams PS: Theoretical basis of field-flow fractionation. In: Theoretical Advancement in Chromatography and Related Separation Techniques. Dondi F and Guiochon G (eds). NATO ASI Ser., Ser. C: Mathematical and Physical Sciences. Kluwer, Dordrecht, pp513-580, 1992. 
22. Plockova J, Matulik F and Chmelik J: Different elution modes and field programming in gravitational field-flow fractionation IV. Field programming achieved with channels of non-constant cross-sections. J Chromatogr A 955: 95-103, 2002.

23. Schure MR, Caldwell KD and Giddings JC: Theory of sedimentation hyperlayer field-flow fractionation. Anal Chem 58: 1509-1516, 1986.

24. Tong X and Caldwell KD: Separation and characterization of red blood cells with different membrane deformability using steric field-flow fractionation. J Chromatogr B 674: 39-47, 1995.

25. Williams PS, Lee S and Giddings JC: Characterization of hydrodynamic lift forces by field-flow fractionation. Inertial and near-wall lift forces. Chem Eng Commun 130: 143-166, 1994.

26. Chmelik J: Different elution modes and field programming in gravitational field-flow fractionation; I. A theoretical approach. J Chromatogr A 845: 285-291, 1999.

27. Reschiglian P, Zattoni A, Roda B, Michelini E and Roda A: Field-flow fractionation and biotechnology. Trends Biotechnol 23: 475-483, 2005.

28. Battu S, Cook-Moreau J and Cardot PJP: Sedimentation fieldflow fractionation: methodological basis and applications for cell sorting. J Liq Chromatogr R T 25: 2193-2210, 2002.

29. Comte I, Battu S, Mathonnet M, Bessette B, Lalloue F, Cardot P and Ayer-Le Lievre C: Neural stem cell separation from the embryonic avian olfactory epithelium by sedimentation fieldflow fractionation. J Chromatogr B 843: 175-182, 2006.

30. Roda A, Parisi D, Guardigli M, Zattoni A and Reschiglian P: Combined approach to the analysis of recombinant protein drugs using hollow-fiber flow field-flow fractionation, mass spectrometry, and chemiluminescence detection. Anal Chem 78: 1085-1092, 2006.

31. Li S, Nickels J and Palmer AF: Liposome-encapsulated actinhemoglobin (LEAcHb) artificial blood substitutes. Biomaterials 26: 3759-3769, 2005.

32. Andersson CIJ, Arfvidsson C, Kallio PT, Wahlund KG and Buelow L: Enhanced ribosome and tRNA contents in Escherichia coli expressing a truncated Vitreoscilla hemoglobin mutant analyzed by flow field-flow fractionation. Biotechnol Lett 25: 1499-1504, 2003.

33. Andersson M, Fromell K, Gullberg E, Artursson P and Caldwell KD: Characterization of surface-modified nanoparticles for in vivo biointeraction. A sedimentation field flow fractionation study. Anal Chem 77: 5488-5493, 2005

34. Arfvidsson C and Wahlund Karl G: Time-minimized determination of ribosome and tRNA levels in bacterial cells using flow fieldflow fractionation. Anal Biochem 313: 76-85, 2003.

35. Chen Z and Chauhan A: DNA separation by EFFF in a microchannel. J Colloid Interface Sci 285: 834-844, 2005.

36. Farmakis L and Koliadima A: Kinetic study of cell proliferation of Saccharomyces cerevisiae strains by sedimentation/steric field flow fractionation in situ. Biotechnol Prog 21: 971-977, 2005.

37. Garcia MT, Sanz R, Galceran MT and Puignou L: Use of fluorescent probes for determination of yeast cell viability by gravitational field-flow fractionation. Biotechnol Progr 22: 847-852, 2006.

38. Guglielmi L, Battu S, Le Bert M, Faucher JL, Cardot PJP and Denizot Y: Mouse embryonic stem cell sorting for the generation of transgenic mice by sedimentation field-flow fractionation. Anal Chem 76: 1580-1585, 2004

39. Gascoyne P, Satayavivad J and Ruchirawat M: Microfluidic approaches to malaria detection. Acta Trop 89: 357-369, 2004.

40. Kang D and Moon MH: Hollow fiber flow field-flow fractionation of proteins using a Microbore channel. Anal Chem 77: 4207-4212, 2005.

41. Huang Y, Yang J, Wang XB, Becker FF and Gascoyne PR: The removal of human breast cancer cells from hematopoietic CD34+ stem cells by dielectrophoretic field-flow-fractionation. J Hematoth Stem Cell 8: 481-490, 1999.

42. Luo J, Leeman M, Ballagi A, Elfwing A, Su Z, Janson J-C and Wahlund K-G: Size characterization of green fluorescent protein inclusion bodies in $E$. coli using asymmetrical flow field-flow fractionation-multi-angle light scattering. J Chromatogr A 1120: $158-164,2006$

43. Lee H, Williams SKR, Wahl KL and Valentine NB: Analysis of whole bacterial cells by flow field-flow fractionation and matrix-assisted laser desorption/ionization time-of-flight mass spectrometry. Anal Chem 75: 2746-2752, 2003.
44. Reschiglian P, Zattoni A, Roda B, Cinque L, Melucci D, Min Byung R and Moon Myeong H: Hyperlayer hollow-fiber flow field-flow fractionation of cells. J Chromatogr A 985: 519-529, 2003

45. Sanz R, Cardot P, Battu S and Galceran MT: Steric-hyperlayer sedimentation field flow fractionation and flow cytometry analysis Applied to the study of Saccharomyces cerevisiae. Anal Chem 74: 4496-4504, 2002

46. Yohannes G, Sneck M, Varjo SJO, Jussila M, Wiedmer SK, Kovanen PT, Oeoerni K and Riekkola M-L: Miniaturization of asymmetrical flow field-flow fractionation and application to studies on lipoprotein aggregation and fusion. Anal Biochem 354: 255-265, 2006

47. Yang J, Huang Y, Wang X-B, Becker FF and Gascoyne PRC Cell separation on microfabricated electrodes using dielectrophoretic/gravitational field-flow fractionation. Anal Chem 71: 911-918, 1999.

48. Battu S, Elyaman W, Hugon J and Cardot PJP: Cortical cell elution by sedimentation field-flow fractionation. Biochim Biophys Acta 1528: 89-96, 2001

49. Lautrette C, Cardot PJP, Vermot-desroche C, Wijdenes J, Jauberteau MO and Battu S: SdFFF Purification of immature neural cells from a human tumor neuroblastoma cell line. $\mathrm{J}$ Chromatogr B 791: 149-160, 2003

50. Giraud S, Bessette B, Boda C, Lalloue F, Petit D, Mathonnet M and Jauberteau MO: In vitro apoptotic induction of human glioblastoma cells by Fas ligand plus etoposide and in vivo antitumour activity of combined drugs in xenografted nude rats. Int J Oncol 30: 273-281, 2007.

51. Corbière C, Battu S, Liagre B, Cardot PJP and Beneytout JL: SdFFF monitoring of cellular apoptosis induction by diosgenin and different inducers in the human 1547 osteosarcoma cell line. J Chromatogr B 808: 255-262, 2004.

52. Bégaud-Grimaud G, Battu S, Liagre B, Leger DY, Beneytout JL and Cardot PJP: Pre-apoptotic sub-population cell sorting from diosgenin apoptosis induced 1547 cells by two Sedimentation Field-Flow Fractionation devices. J Chromatogr A 1128: 194-202, 2006.

53. Leger DY, Liagre B, Cardot PJP, Beneytout JL and Battu S: Diosgenin dose-dependent apoptosis and differentiation induction in HEL cell line and SdFFF monitoring. Anal Biochem 335 267-278, 2004.

54. Leger DY, Battu S, Liagre B, Beneytout JL and Cardot PJP: Megakaryocyte cell sorting from diosgenin-differentiated human erythroleukemia cells by sedimentation field-flow fractionation. Anal Bioche 355: 19-28, 2006.

55. Harold C, Chazala G, Goridisa C and Represa A: NCAM is essential for exonal growth and fasciculation in the hippocampus. Mol Cell Neurosci 8: 323-335, 2002.

56. Ronn LC, Berezin E and Bock E: The neural cell adhesion molecule in synaptic plasticity and ageing. Int J Dev Neurosci 18: 193-199, 2000 .

57. Thomas SK, Messam CA, Spengler BA, Biedler JL and Ross RA Nestin is a potential mediator of malignancy in human neuroblastoma cells. J Biol Chem 279: 27994-27999, 2004.

58. Kim HR, Kim EJ, Yang SH, Jeong ET, Park C, Kim SJ, Youn MJ, So HS and Park R: Combination treatment with arsenic trioxide and sulindac augments their apoptotic potential in lung cancer cells through activation of caspase cascade and mitochondrial dysfunction. Int J Oncol 28: 1401-1408, 2006.

59. Goillot E, Raingeaud J, Ranger A, Tepper RI, Davis RJ, Harlow E and Sanchez I: Mitogen-activated protein kinasemediated Fas apoptotic signaling pathway. Proc Natl Acad Sci USA 94: 3302-3307, 1997.

60. Cheema ZF, Wade SB, Sata M, Walsh K, Sohrabji F and Miranda RC: Fas/Apo [apoptosis]-1 and associated proteins in the differentiating cerebral cortex: induction of caspasedependent cell death and activation of NF-kappaB. J Neurosci Res 19: 1754-1770, 1999.

61. Gallagher HC, Odumeru OA and Regan CM: Regulation of neural cell adhesion molecule polysialylation state by cell-cell contact and protein kinase C delta. J Neurosci Res 61: 636-645, 2000

62. Bonfanti L: PSA-NCAM in mammalian structural plasticity and neurogenesis. Prog Neurobiol 80: 129-164, 2006. 